\title{
A CONTRIBUIÇÃO DA NEUROLINGUÍSTICA NO ENTENDIMENTO DO PROCESSO DE LEITURA E COMPREENSÃO TEXTUAL
}

\author{
THE CONTRIBUTION OF NEUROLINGUISTICS IN UNDERSTANDING THE PROCESS OF \\ READING AND TEXTUAL COMPREHENSION
}

Catyane Roberta Hauth

Prefeitura Municipal de Sinop, MT, Brasil. E-mail: catyhauth@gmail.com

\begin{abstract}
Rodi Narciso
Faculdade Venda Nova do Imigrante, MG, Brasil. E-mail: rodynarciso1974@gmail.com
\end{abstract}

DOI: https://doi.org/10.46550/amormundi.v2i4.102

Recebido em: 04.03.2021

Aceito em: 16.04.2021

\begin{abstract}
Resumo: Neurolinguística é uma ciência oriunda das Neurociências e da Linguística responsável por pesquisar os mecanismos neurofisiológicos incumbidos da aquisição e processamento da linguagem. O presente estudo trata de expor, de maneira sucinta, os resultados dos estudos provenientes desta nova ciência, buscando explanar seus campos de investigação nas questóes que abordam o processo de obtenção, uso, leitura e compreensáo textual. Com isso, objetivou-se elaborar um texto puramente bibliográfico, seguindo esta ordem temática: definição do que é Neurolinguística e seus pressupostos teóricos-metodológicos oriundos da Neurociência e da Linguística. Seguido da concepção de comunicação e linguagem (processamento/compreensão da linguagem oral e escrita), pelo viés neurocientífico e neurolinguístico. A posteriori, apresentou-se a questão social que engloba a inevitabilidade do ato de ler e escrever na formação do leitor, assim como a carência de informaçôes sobre essa necessidade. Sucedido, finalmente, pela apresentaçáo dos efeitos causados pela leitura no cérebro, a curto e longo prazo, elencados pela neurolinguística e neurociência. Esta pesquisa busca responder a seguinte questão norteadora: Qual a contribuição da neurociência, linguística para a neurolinguística no conhecimento/entendimento do processo de leitura e interpretaçâo textual? Da qual conclui-se que é inegável o avanço alcançado pela neurolinguística no que tange ao processo de aquisição, processamento e uso da linguagem; logo será possível compreender todos os processos sofridos pelo cérebro no processo de leitura e compreensão textual, e de semelhante modo, enfatizar da importância da formação de leitores linguisticamente aptos.
\end{abstract}

Palavras-chave: Neurolinguística. Linguagem. Leitura. Compreensão.

Absract: Neurolinguistics is the junction of Neurosciences and Linguistics responsible for researching the neurophysiological mechanisms responsible for language acquisition and processing. This study succinctly exposes the results of studies from this new science, seeking to explain its fields of investigation in issues that address the process of obtaining, using, reading and text comprehension. Wich was to prepare a purely bibliographical text, following this thematic order: definition of what Neurolinguistics is and its theoretical-methodological assumptions from Neuroscience and Linguistics. Followed by the conception of communication and language (processing/comprehension of oral and written language), by the neuroscientific and neurolinguistic. A posteriori, 
the social issue that encompasses the inevitability of the act of reading and writing in the reader's education is presented, as well as the lack of information about this need. Finally, it was followed by the presentation of the effects caused by reading on the brain, in the short and long term, listed by neurolinguistics and neuroscience. This research seeks to answer the following guiding question: What is the contribution of neuroscience, linguistics to neurolinguistics in the knowledge/understanding of the reading process and textual interpretation? From which it is concluded that the advances achieved by neurolinguistics regarding the acquisition, processing and use of language are undeniable; soon it will be possible to understand all the processes suffered by the brain in the process of reading and text comprehension, and similarly, emphasize the importance of training linguistically able readers.

Keywords: Neurolinguistics. Language. Reading. Understanding.

\section{Introduçáo}

Dartindo do princípio de a Neurolinguística ser ramificação da neurociência e da Linguística, esta responsável por pesquisar os mecanismos neurofisiológicos incumbidos pela aquisição, processamento e uso da linguagem, tanto escrita como oral; e que este viés se destina por tentar responder, dentro dos limites da própria ciência - em plena expansão neste momento, indagaçôes como "o que acontece com o cérebro quando escrevemos ou lemos algo?”, é que nos pautamos para a redação deste estudo para obtenção de título de especialista em Neurolinguística.

Dessarte, estudos sobre os mecanismos neurofisiológicos encarregados pela aquisição, uso e processamento da linguagem vêm sendo formulados, já indicando ser esta uma das áreas mais produtivas (no tangente a campo de estudo/pesquisa), advindas desta década.

França (2005, p. 20), disserta que por intermédio de "registros da atividade bioelétrica no córtex e dos padróes do fluxo sanguíneo no interior do cérebro, aferidos por técnicas como a eletroencefalografia, a ressonância magnética funcional e outras, permitem identificar o modo e a localização da ativação cerebral enquanto ouvimos e produzimos a linguagem".

A Neurolinguística, consoante com Pinto (2011, p. 966), afamada como “área híbrida”, situa-se em um campo de conflitos epistemológicos. Entre eles tem-se o enfrentamento teóricometodológico, fruto de arquétipos provenientes das Neurociências e Linguística em si. Ou seja, mesmo partilhando interesses em comum, como a relação entre o cérebro, a linguagem e a cognição; acham-se algumas barreiras que dificultam o pleno diálogo destas ciências, como por exemplo o tabu historicamente imposto pela comunidade científica em geral de que as ciências humanas e as biológicas não podem interagir.

Todavia, não é o objetivo deste artigo levantar discussão acerca destes conflitos, e sim, confirmar, com base em estudos já realizados, a importância da neurociência, linguística e neurolinguística na compreensão do que acontece ao cérebro durante e depois da leitura de livros.

Aspirando estes propósitos, este estudo de caráter bibliográfico, buscar clarificar demandas pertinentes ao tema em questão. E, que para tanto, é vital que hajam explanaçóes que visem, primeiramente, o caráter teórico metodológico da neurolinguística provenientes da neurociência e linguística. Porquanto, uma vez sendo esta uma área contemporânea, cabe a conscientização de que as fontes de pesquisa sobre a mesma ainda são escassas. E que, portanto, reunir-se-á nestas páginas o que foi possível ser encontrado, dentro das três ciências em pauta, de 


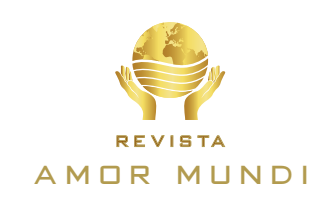

materiais que atendam e respondam as especificidades do questionamento norteador da pesquisa: Qual a contribuição da neurociência, linguística para a neurolinguística no conhecimento e entendimento do processo de leitura e interpretação textual?

Partindo desta situação/problema, intentou-se apresentar as contribuições desta ciência no que tange ao processo de aquisição e processamento da linguagem, em harmonia com a importância do ato de ler e seu desenvolvimento à luz da neurolinguística e neurociência, dispondo de autores referenciais da área como: Moutinho (2016), Dehaene (2012), Krug (2015), Coelho e Correa (2017), Berns et. al. (2013), dentre outros. Não deixando, obviamente, de citar, sempre que o assunto é linguagem e aquisição da mesma, um grande percursor do tema, Vygotsky (2000 - 2007).

Discorrendo sobre a área em questão, vislumbrou-se que algo considerado tão banal como a fala é, na verdade, mais complexo do que se imagina; e sendo assim, o processo de leitura e escrita se enquadram nesta mesma complexidade. Que embora o vocabulário médio de um adulto chega a ter 40 unidades distintivas de fala, uma criança, obviamente com um número muito menos de unidades fonéticas, consegue integrar-se em sua comunidade linguística tranquilamente, isso graças as associaçóes de panoramas neurolinguísticos presentes no seu cérebro, que, na comunicação humana, tanto falada como escrita, é caracterizada pela plasticidade. Este dado é obtido graças ao avanço das neurociências e de seus exames de neuroimagens que captam a atividade do cérebro no momento de leitura e escrita- in loco.

Quanto ao processamento da fala, França (2005, p. 21), discorre que,

Além disso, enquanto processamos a fala, que chega ao cérebro através dos ouvidos, pensamos e produzimos outros conteúdos, observando critérios de qualidade de cunho estrutural, discursivo e contextual. E fazemos tudo isso mantendo o fluxo da comunicação ininterrupto, em uma velocidade média de cinco sílabas por segundo! Sempre encontramos recursos cognitivos para vencer a enorme pressão do tempo imposta pelos padrôes da comunicação oral.

Em outras palavras, para se compreender uma palavra lida ou ouvida urge que precisemos ter acesso ao nosso repertório de representaçôes mentais daquela palavra em questão, e tudo isso numa velocidade fantástica.

Para tal, é preciso uma estratégica de alta performance de ativação, competição e supressão de conteúdos mentais, que oportunizam a obtenção do significado que buscamos. E “[...] ao tentarmos ativar a representação da palavra-alvo, ativamos outras, que competem entre si por reconhecimento. Ao final do processo, a palavra-alvo sobressai, pois atinge o máximo nível de ativação e é então reconhecida." (FRANÇA, 2005, p. 21). Isso tudo à luz da neurociência, linguística e neurolinguística.

Também será abordado que tanto a neurociência quanto a neurolinguística elucidam que após a leitura de livros, os mesmos deixam "marcas”, literalmente, em nosso cérebro, explicitado através de estudos de grandes nomes das áreas supracitadas.

Isto posto, este artigo será disposto na seguinte ordem: num primeiro momento a definição do que é Neurolinguística e seus pressupostos teóricos-metodológicos emergentes da Neurociência e da Linguística; seguido pela concepção de comunicação e linguagem 
(processamento/compreensão da linguagem oral e escrita), pelo viés neurocientífico e neurolinguístico. Conseguinte pela abordagem da questão social que engloba a necessidade do ato de ler e escrever na formação do leitor, assim como a carência de informaçóes sobre essa necessidade. Sucedido, finalmente, pela apresentaçáo dos efeitos causados no cérebro pela leitura, a curto e longo prazo, elencados pela neurolinguística e neurociência.

À vista disso, ter-se-á a conclusão do estudo, que visará apresentar as percepçôes obtidas acerca do tema pesquisado.

\section{Desenvolvimento}

Tipificada como bibliográfica esta pesquisa propóe-se atender os objetivos propostos no início do curso de pós-graduação. A questão-problema aqui levantada oriunda de curiosidade particular com relação ao tema, influenciando diretamente na escolha do curso e, consequentemente, na redação deste artigo.

Posto que, ao se tratar de uma pesquisa bibliográfica, a mesma apresentará teorias e estudos já realizados que abordam o percurso da neurolinguística e seus pressupostos teóricosmetodológicos desde seu desmembramento da neurociência, assim como o contexto histórico de língua, linguagem e sujeito no processo de aquisição, processamento e uso da linguagem. Chegando, enfim, no âmago da presente pesquisa, que será versado no processo de leitura e interpretação textual, mais especificamente: o que acontece no cérebro durante e depois este processo.

Com relação a classificação desta pesquisa como bibliográfica, muitos são os autores que comentam suas especificidades. Dentre eles Boccato (2006, p. 266), que argumenta que esta,

[...] busca a resolução de um problema (hipótese) por meio de referenciais teóricos publicados, analisando e discutindo as várias contribuições científicas. Esse tipo de pesquisa trará subsídios para o conhecimento sobre o que foi pesquisado, como e sob que enfoque e/ou perspectivas foi tratado o assunto apresentado na literatura científica. Para tanto, é de suma importância que o pesquisador realize um planejamento sistemático do processo de pesquisa, compreendendo desde a definição temática, passando pela construção lógica do trabalho até a decisão da sua forma de comunicação e divulgação.

Assim sendo, essa modalidade de pesquisa é realizada com o auxílio de fontes documentais como: websites ${ }^{l}$ acadêmicos, bibliotecas, hemerotecas, livros físicos, dentre outros.

O critério de escolha dos textos de base para o desenvolvimento deste estudo foram a relevância destes no meio acadêmico, as datas de publicação, e, acima de tudo, o caráter social e cultural, visando sempre a expansão de horizontes; sempre partindo do ponto de apresentação e reflexão dos fatos.

\subsection{A importância do ato de ler: explicando neurolinguisticamente todas as etapas deste processo}

Sendo uma ciência relativamente jovem e tendo uma área heteróclita, a Neurolinguística se encontra num ambiente de constante enfrentamentos no tocante aos seus pressupostos teóricos

1 Website: "palavra que resulta da justaposição das palavras inglesas web(rede) e site (sítio, lugar). [...] referência a uma página ou a um agrupamento de páginas relacionadas entre si, acessíveis na internet através de um determinado endereço”. Disponível em:< https://www.significados.com.br/website/. 
metodológicos e sobre suas ciências constituintes- Neurociência e Linguística.

Embora compartilhem do interesse acerca de muitos objetos - dentre os quais a relação entre cérebro, linguagem e cognição - há muitas barreiras que dificultam o diálogo entre esses campos de saber, com destaque para as questóes acerca do método para abordar os fenômenos linguístico-cognitivos. (PINTO, 2011. p.966- grifo do autor).

Não obstante, não cabe aqui levantar questionamento com relação a estes conflitos, e sim, delimitar a área de atuação de cada uma destas ciências e seu papel no processo de aquisição, uso e processamento da linguagem do sujeito.

Logo, o pressuposto teórico metodológico desta pesquisa se pauta em conhecer a base biológica e psicológica da linguagem e da língua. Entretanto, embora exista uma concepção errônea de que as ciências humanas e biológicas não podem se associar, buscou-se transpor essa barreira cultural para explicar a aprendizagem e o funcionamento do cérebro no processo de leitura e compreensão textual, e suas "marcas" deixadas no cérebro após este processo.

Changeux (2012, p. 9) desfia que,

Sem dúvida, em virtude do dualismo platônico, a tradição ocidental estabeleceu uma separação - que eu não hesitaria de qualificar como trágica - entre as ciências do homem e as ciências biológicas, a tal ponto que por muito tempo houve um acordo em opor o biológico ao cultural, a natureza à cultura, os genes à aprendizagem. Um dos pontos fortes das neurociências contemporâneas - a obra de Stanislas Dehaene o revela otimamente - é o de haver demonstrado que, no homem, o cultural não pode ser pensado sem o biológico e que o cerebral não existe sem uma impregnação poderosa do ambiente.

Uma vez exposta essa questão, infere-se que somente será possível entender e responder a todas as questôes acerca de a espécie humana ser a única capaz de produzir cultura se houver a ruptura de paradigmas historicamente impostos no meio acadêmico e buscar-se explorar, com a ajuda da junção destas duas áreas, e as ciências-fonte da neurolinguística, de como se estrutura, funciona e é utilizado o cérebro humano no tocante a fala, escrita e leitura.

Tratando-se da linguagem verbal, a mesma detém o senhorio e especialidade oriundas de suas áreas secundárias e terciárias cerebrais, localizadas no hemisfério esquerdo integrando as áreas terciárias. (SCLIAR-CABRAL, 2010).

Por mérito da Neurociência sabe-se que os neurônios localizados na região occipitotemporal ventral esquerda, incumbindo-se de reconhecer os traços invariantes que constituem as letras, e que os valores são idênticos, para realizar a decodificação dos signos. (DEHAENE, 2012).

A inevitabilidade de reconhecimento destas informaçóes pelo cérebro se dão por duas razóes: primeira, como mecanismo adaptativo para reconhecimento de formas básicas existentes na natureza (distância, ângulo, etc.); e segunda, sendo esta especificamente humana, o reconhecimento por parte dos neurônios da regiáo occipitotemporal ventral dos traços invariantes que constituem as letras, onde os axônios (prolongamentos dos neurônios transporta a informação a outros neurônios através das sinapses), fazem ligação a todas a regiôes responsáveis pela linguagem verbal e seus significados, processados simultaneamente.

Para que este processo aconteça é imperioso que ocorra mudanças neurais, estas que não são caracterizadas pela evoluão na espécie (filogenética), e sim, por uma espécie de "reciclagem" neurológica que é atribuída ao processo de aprendizagem. (MORAIS, et. al. 2010). Logo, no 
tocante a leitura, não existe momento propício ou não destas evoluçôes serem mais ou menos eficazes ou prazerosas, uma vez que essas mudanças ocorrem em toda vida do sujeito leitor (demonstrando assim a plasticidade cerebral).

Adentrando na questão metodológica, tendo por ponto de ancoragem as contribuiçôes da Linguística e a neurolinguística discursiva, o aprendizado da leitura e escrita consoante a Vygotsky (2007), apresenta um termo a ser considerado. De acordo com o teórico (2007), a aquisição da capacidade de ler e escrever não ocorre de maneira linear, e sim por ritmos variados, tendo momentos e declínio e ascensão, fazendo deste processo constante, heterogêneo e com inúmeras hipóteses previsíveis e imprevisíveis.

Moutinho (2016, p.297), exterioriza que, “[...] este período é caracterizado não por trocas, mas por instabilidades ortográficas, que, à medida que a criança passa a ler mais e fica exposta às palavras, às frases e aos textos escritos, desaparecem e dão lugar à ortografia convencional.”

Uma vez conhecidas as mazelas sociais referentes ao processo de não-letramento e analfabetismo da sociedade, é de comum conhecimento que muitas crianças possuem uma família que não lê nem tampouco escreve, não tem material impresso/escrito em casa (livros, revistas, jornais, etc.), o que influi diretamente no aprendizado e qualidade destas duas habilidades. Sendo que, através do contato com o papel, no qual a língua escrita se encontra registrada, sendo possível a posse e entendimento das regras ortográficas.

E, partindo desta afirmativa, conferimos caráter substancial a leitura, sendo ela responsável pelo processo de formação do indivíduo, tornando-o apto a analisar seu ambiente, e, mais especificamente, corroborando para a diversificação de visôes e interpretaçôes dos contextos de mundo que lhe são apresentados, diversificando visóes e interpretaçôes sobre o mundo e sobre si mesmo. (KRUG, 2015).

Dentro desse contexto, "ler" e "ser leitor" possuem discrepâncias passíveis de consideração. Onde aquela trata-se do ato de decodificação da mensagem simbólica impressa por meio de letras/ sílabas/palavras/frases; enquanto esta é caracterizada pelo aprender a ler de fato, onde o leitor é conduzido a compreender, interpretar e inserir-se (abstratamente) no campo do pensamento e imaginação.

Segundo Krug (2015, p.3), a leitura,

[...] constitui também uma prática social, pela qual o sujeito, ao praticar o ato de ler, mergulha no processo de produção de sentidos, e esta tornar-se-á algo inscrito na dimensão simbólica das atividades humanas. Sendo assim, falar em atividades humanas, aqui, é tratar de uma linguagem, do recurso pelo qual o homem adentra o universo da cultura, configurando-se com um ser culto, racional e pensante.

É por intermédio da leitura, argumenta Koch e Elias (2008), que além de fazer parte da vida do leitor e lhe conferir cultura e conhecimento, proporciona-lhe mecanismo de uniáo entre os sujeitos sociáveis com a linguagem sociocognitiva, possibilitando o contato com elementos carregados de significas no interior do texto. Deste modo, quem lê é posto em contato direto com as palavras, de maneira singular, compreendendo o grau de sentido que elas preservam.

Ao ler, é solicitado do leitor que, além dos conhecimentos linguísticos e de mundo, seja constuído sua interpretação daquilo que está tanto explícito na superfície textual, quanto implícito. (ROAZZI, et. al. 2013).

Algumas das principais habilidades relacionadas à decodificação referem-se à consciência 
fonológica, à memória de trabalho e à nomeação automatizada rápida, esta última, entendida como parte da velocidade de processamento da informação. (COELHO e CORREA, 2017).

Diante do exposto e, com o auxílio da Neurolinguística e suas ciências-fonte, inferese que ler deixa, literalmente, "marcas" no cérebro humano. Um estudo feito por Berns et. al. (2013), "Short- and Long-Term Effects of a Novel on Connectivity in the Brain" (Efeitos de curto e longo prazo na leitura de um romance na conectividade do cérebro), constatou que o ato de ler influi mudanças de conectividade no cérebro, que continuam a existir mesmo depois de dias passados do término da leitura.

Em sua pesquisa, Berns et. al. (2013), propôs acompanhar os efeitos naturais causados ao cérebro após ler um romance baseado em fatos reais. No decorrer de nove dias, vinte e um participantes leram o romance Pompéia, escrito por Robert Harris. A presente obra narra um evento verídico, a erupção do Monte Vesúvio na Itália, acompanhando o protagonista que, de fora da cidade de Pompéia, percebe a fumaça ao redor do vulcáo e tenta voltar para salvar sua amada.

Para participarem da pesquisa, os participantes deviam ler a obra pela noite, e, na manhã seguinte, serem submetidos a exames de ressonância magnética. Após o término destes nove dias, os mesmos participantes permaneceram por mais outros cinco dias no laboratório do pesquisador para que este aferisse se os efeitos da história permaneceriam em suas conectividades cerebrais.

Para constataçáo das suspeitas do mesmo, os resultados mostraram um aumento de conectividade de uma região do cérebro associada à recepção da linguagem. Ou seja, mesmo náo estando mais lendo o livro, os cérebros avaliados mantiveram o aumento de conectividade.

Berns et. al. (2013, p.597-598), discorre que houve aumento de conexóes identificado no sulco central do cérebro, regiâo ligada à função motora. Os neurônios dessa região estão relacionados à criação de representaçóes de uma sensação do corpo.

[...] of nodes and connections with significantly increased correlation during story versus nonstory days. This sparse network was located in posterior temporal gyri with connections to the central sulcus. The time-course of correlations across days showed a sharp rise beginning on the first post-story that was sustained at a relatively constant level throughout the story, followed by a sharp decline poststory. [...] conexöes significativamente aumentadas durante a história versus depois da leitura. Esta rede esparsa localizava-se em giros temporais posteriores com conexóes no sulco central(sensaçôes). O tempo das correlaçôes durantes os dias mostrou um aumento acentuado a partir do primeiro dia pós-história que foi sustentado em um nivel relativamente constante ao longo da história, seguido por um declinio acentuado pós-história. (grifo próprio e tradução livre)

Tais mudanças cerebrais provocadas pela leitura, em conformidade com Berns et. al. (2013), correspondem a movimentação e sensaçóes físicas, provam que um romance pode fazer com que o leitor se sinta na pele do protagonista (biologicamente).

Portanto, embora ainda não se possa afirmar até onde as mudanças podem ir, uma coisa é certa: elas persistiram pelo menos cinco dias após a leitura. Assim sendo, o estudo ainda se mostra aberto com relação a esta área.

It remains an open question for further study as to how lasting these effects are, but our results suggest a potential mechanism by which reading stories not only strengthen language processing regions but also affect the individual through embodied semantics in sensorimotor regions. Isso continua a ser uma questão em 
aberto para um estudo mais aprofundado sobre a duração desses efeitos, mas nossos resultados sugerem um mecanismo potencial pelo qual a leitura histórias não só fortalece regiöes de processamento de linguagem, mas também, afetam o individuo através da semântica incorporada nas regióes sensório-motoras. (BERNS et. al. 2013, p 599. Grifo próprio e tradução Livre)

Logo, como visto no decorrer deste trabalho, a relevância da leitura e suas contribuições para a formação do leitor, além de influir na sua comunicação e entendimento para com o próximo, mostrar-se importante na composição linguística e metalinguística da fala e da escrita do sujeito. Uma vez tendo essas três perspectivas que norteiam e enaltecem o ato de ler é que esse processo, à luz da Neurolinguística, Linguística e Neurociência, fora aqui apresentado e comentado.

\section{Conclusão}

A linguagem em si é fruto da necessidade comunicacional inerente ao ser humano. A mesma encontra-se estruturada de maneira operacional dentro de um determinado grupo, tendo em vista o ponto de vista cultural e social deste. (VYGOTSKY, 2000).

Dessarte, é possível concluir que os processos de escrita e leitura deram início a um novo capítulo, ainda em construção, no estudo sobre a humanidade.

No decorrer deste estudo, pode-se contemplar a relevância do ato de ler e escrever, consoante com suas implicaçóes na formação do leitor. Este que é influenciado diretamente em sua maneira de comunicar-se com seus semelhantes, através de sua construção linguística da fala, bem como pela influência exercida pela leitura na construção da escrita.

Adentrando mais especificamente ao campo da neurolinguística, linguística e neurociência, é possível evidenciar sua importância no conhecimento sobre o processo de leitura e interpretação textual; compreensão do enredo, trama e desfecho da história, assim como no conhecimento das personagens e sequência de eventos que as circundam.

A neurolinguística demonstra que essas capacidades de desconsciência fonêmica e nomeação automatizada rápida garantem a compreensão do texto lido. Essas habilidades estão agregadas a construção da fluência na leitura, a qual infunde automaticidade do trabalho textual, em nível superficial, sendo possível assim alforriar os recursos cognitivos específicos para a efetivação de habilidades de alta performance. (COELHO e CORREA, 2017).

É indubitável o crescimento da neurolinguística enquanto ciência. Contudo, devido à complexidade da linguagem humana, muito há de ser investigado e, consequentemente, descoberto até se chegar a um conteúdo abrangente sobre a questão do armazenamento, compreensão e produção da linguagem, tanto falada como escrita (leitura), pelo cérebro humano.

Portanto, respondendo à questão norteadora desta pesquisa, conclui-se que o aprendizado da leitura, assim como da escrita, depende da interação de diversas áreas do cérebro e sua compreensão, de igual modo, depende da interação da Neurociência, Linguística e da Neurolinguística.

Num primeiro instante uma área visual específica, classificada como parietal, incumbese de reconhecer as formas visuais das letras. Esta é responsável por se relacionar com a área temporal verbal que produz os sons para que possamos fonar as letras, sílabas e palavras escritas. 
E, posteriormente, visualizar contextos e situaçóes.

Os neurocientistas defendem que a representação de imagens mentais interfere no sistema neuronal cortical e subcortical, ativando uma rede de células "grid", que são neurônios responsáveis por orientar o sujeito no ambiente. Isso acontece por intermédio das imagens mentais criadas durante a leitura ou quando se imagina algum determinado local.

Tendo por pressuposto que a leitura nos marca, a neurociência e neurolinguística demonstram que após a leitura de livros os mesmos deixam "marcas", literalmente, em nosso cérebro. Estudos feitos por Berns et. al. (2013), evidenciaram uma marca neuronal que a leitura de um romance deixava no cérebro dias depois do fim do mesmo em 21 participantes da pesquisa. Ao se realizarem ressonâncias nos mesmos participantes da pesquisa dias após a conclusão da leitura, pode-se verificar que o aumento da conectividade que acontecia no momento da leitura se manteve por vários dias após o término do livro.

Concluindo, por fim, a partir dos assuntos aqui abordados, não se pode afirmar que este estudo esteja finalizado, mas sim, que foi dado o pontapé inicial para a realização de outras pesquisas. Todavia esta pesquisa teve por objetivo, a priori, explanar sobre a importância da neurolinguística no processo de conhecimento da plasticidade de nosso cérebro durante a leitura e escrita, e que a mesma, em conjunto com suas ciências-mãe, contribuem para a construção de novas perspectivas e pesquisas acerca do tema.

\section{Referências}

BERNS, G. S; et. al. (2013). Short- and Long-Term Effects of a Novel on Connectivity in the Brain. BRAIN CONNECTIVITY Volume 3, Number 6. Mary Ann Liebert, Inc. DOI: 10.1089/brain.2013.0166. Recuperado em 26 Abril, 2019, de https://www.ncbi.nlm.nih.gov/ pubmed/23988110. Acesso em: 19 agosto de 2020.

BOCCATO, V. R. C; (2006). Metodologia da pesquisa bibliográfica na área odontológica e o artigo científico como forma de comunicaçáo. Rev. Odontol. Univ. Cidade São Paulo, São Paulo, v. 18, n. 3, p. 265-274. Recuperado em 26 Abril, 2019, de http:// arquivos.cruzeirodosuleducacional.edu.br/principal/old/revista_odontologia/pdf/setembro_ dezembro_2006/metodologia_pesquisa_bibliografica.pdf. Acesso em: 19 agosto de 2020.

CHANGEUX, J.P. In: DEHAENE, S. (2012). Os neurônios da leitura. Trad. de SCLIARCABRAL, Leonor. Porto Alegre: Penso.

COELHO, C. L. G; CORREA, J. (2017). Compreensão de leitura: Habilidades cognitivas e tipos de texto. Revista Psico. Porto Alegre, 48(1), 40-49. Recuperado em 26 Abril, 2019, de http://revistaseletronicas.pucrs.br/fo/ojs/index.php/revistapsico/article/view/23417. Acesso em: 19 agosto de 2020 .

DEHAENE, S. (2012). Os neurônios da leitura. Trad. de Leonor Scliar-Cabral. Porto Alegre: Penso.

FRANÇA, A.I. FLAGRANTE DA LINGUAGEM NO CÉREBRO. (2005). Projeto Concatenaçôes Linguísticas: Psicolingüistica e Neurofisiologia (Clipsen), Departamento de Linguística, Universidade Federal do Rio de Janeiro. Recuperado em 26 Abril, 2019, de http:// cienciahoje.org.br/artigo/flagrante-da-linguagem-no-cerebro/. Acesso em: 19 agosto de 2020. 
KOCH, I. G; ELIAS, V. M. (2011). Ler e escrever: estratégias de produçáo textual. São Paulo: Contexto.

KRUG, F. S. (2015). A Importância da Leitura na formação do leitor. Revista de Educação do Ideau - REI- vol. 10 - No 22 - Jul-/Dez. p.1-13. Recuperado em 26 Abril, 2019, de https:// www.ideau.com.br/getulio/restrito/upload/revistasartigos/277_1.pdf. Acesso em: 19 agosto de 2020 .

MORAIS, J; et. al. (2010). International Journal of Arts and Technology, v. 3, n. 2/3. National Society for Art Education. Recuperado em 26 Abril, 2019, de https://www. researchgate.net/journal/14768070_International_Journal_of_Art_Design_Education. Acesso em: 19 agosto de 2020 .

MOUTINHO, I. C. N. (2016). CONTRIBUIÇÓES DA NEUROLINGUÍSTICA DISCURSIVA PARA A FORMAÇÁO DE PROFESSORES. Revista Pesquisa Qualitativa. São Paulo (SP), v. 4, n. 6, p. 289-310, dez.

PINTO, R. C. N. (2011). Desafios metodológicos da pesquisa em Neurolinguística no início do século XXI. ESTUDOS LINGUÍSTICOS, São Paulo, 40 (2): p. 966-980, Mai/ Ago. Recuperado em 26 Abril, 2019, de https://revistas.gel.org.br/estudos-linguisticos/article/ view/1354. Acesso em: 19 agosto de 2020.

ROAZZI, A; et. al. (2013). Compreensão de texto e modelos teóricos explicativos: a influência de fatores linguísticos, cognitivos e metacognitivos. In: MOTA M. \& SPINILLO, A. G. Compreensão de textos. São Paulo: Casa do Psicólogo.

SCLIAR-CABRAL, L. (2013). Avanços das neurociências para a alfabetizaçáo e a leitura. Revista Letras de Hoje, v. 48, n. 3, p. 277-282, Jul/Set. Recuperado em 26 Abril, 2019, de http://revistaseletronicas.pucrs.br/ojs/index.php/fale/article/viewFile/12634/9905. Acesso em: 19 setembro de 2020 .

VYGOTSKY, L. (2007). A formaçáo social da mente: o desenvolvimento dos processos psicológicos superiores. 7. ed. São Paulo: Martins Fontes.

VYGOTSKY, L. (2000). A formaçáo social da mente. São Paulo. Martins Fontes. 